\title{
NUCLEAR THEORY - NUCLEAR POWER
}

\author{
J.P. Svenne ${ }^{1}$, L. Canton ${ }^{2}$ and K.S. Kozier ${ }^{3}$ \\ ${ }^{1}$ Department of Physics and Astronomy, University of Manitoba, \\ and Winnipeg Institute for Theoretical Physics, Winnipeg, Manitoba, \\ Canada R3T 2N2 (Foreign Member of the Latvian Academy of Sciences) \\ ${ }^{2}$ Istituto Nazionale di Fisica Nucleare, sezione di Padova \\ e Dipartimento di Fisica dell'Università di Padova, \\ via Marzolo 8, I-35131 Padova, Italia \\ ${ }^{3}$ Atomic Energy of Canada Limited, Chalk River Laboratories, \\ Chalk River, ON, Canada K0J 1J0
}

\begin{abstract}
The results from modern nuclear theory are accurate and reliable enough to be used for practical applications, in particular for scattering that involves few-nucleon systems of importance to nuclear power. Using well-established nucleon-nucleon $(\mathrm{NN})$ interactions that fit well the NN scattering data, and the AGS form of the threebody theory, we have performed precise calculations of low-energy neutron-deuteron $(n+d)$ scattering. We show that three-nucleon force effects that have impact on the low-energy vector analyzing powers have no practical effects on the angular distribution of the $n+d$ cross-section. There appear to be problems for this scattering in the evaluated nuclear data file (ENDF) libraries, at the incident neutron energies less than 3.2 MeV. Supporting experimental data in this energy region are rather old ( $>25$ years), sparse and often inconsistent. Our three-body results at low energies, $50 \mathrm{keV}$ to $10.0 \mathrm{MeV}$, are compared to the ENDF/B-VII.0 and JENDL (Japanese Evaluated Nuclear Data Library) -3.3 evaluated angular distributions. The impact of these results on the calculated reactivity for various critical systems involving heavy water is shown.
\end{abstract}

\section{INTRODUCTION}

Developments in nuclear theory may seem remote from any practical applications in the near term. Here we present an example of a direct application of current interest (now renewed) in nuclear power as a viable option to the use of $\mathrm{CO}_{2}$-releasing fossil fuels for electric power generation. The theory of nuclear structure and reactions is now accurate enough in many regions of the periodic table to adopt the information derived from theory wherever possible, in the evaluated nuclear data libraries used in practical applications. One such region is the very light nuclei $(A<6)$, where the few-body theory applies.

The specific problem dealt with here is the scattering of low-energy $(E<3 \mathrm{MeV})$ neutrons from deuterium. This is a fundamental problem of nuclear physics, since it is the next-most complex system of nucleons beyond the nucleonnucleon $(\mathrm{NN})$ interaction. It is also a problem of practical importance in heavywater $\left(\mathrm{D}_{2} \mathrm{O}\right)$ moderated nuclear power systems and systems where $\mathrm{D}_{2} \mathrm{O}$ is used as a neutron reflector. In this paper, we outline the variations among the current data 
libraries and between these and the experimental data for low-energy neutrondeuterium $(n+d)$ scattering. We propose using a modern three-nucleon theory to provide additional information on this system. Some implications of these results on the reactor physics calculations will be outlined.

\section{THE NEUTRON-DEUTERON DATABASE}

One might assume that such a simple and fundamental system as neutrondeuteron would have been extensively studied experimentally, and that the evaluated nuclear data libraries (DLs) would be complete and consistent. In fact, that is not so. Most of the experimental data are quite old and there are significant gaps in the data coverage. Also, there are inconsistencies among experimental data sets and between the measured data and the evaluated nuclear DLs. We have looked at the deuterium data in DLs ENDF/B-VI.4, ENDF/B-VI.8 (Evaluated Nuclear Data File/B), and JENDL 3.3 (Japanese Evaluated Nuclear Data Library), in the range from $220 \mathrm{keV}$ to $3.2 \mathrm{MeV}$. Some examples from the second and third of these are shown here. The $n+d$ scattering data of interest in this work are the same for the ENDF/B-VI.5 through VI.8, and ENDF/B-VII.0 DLs.

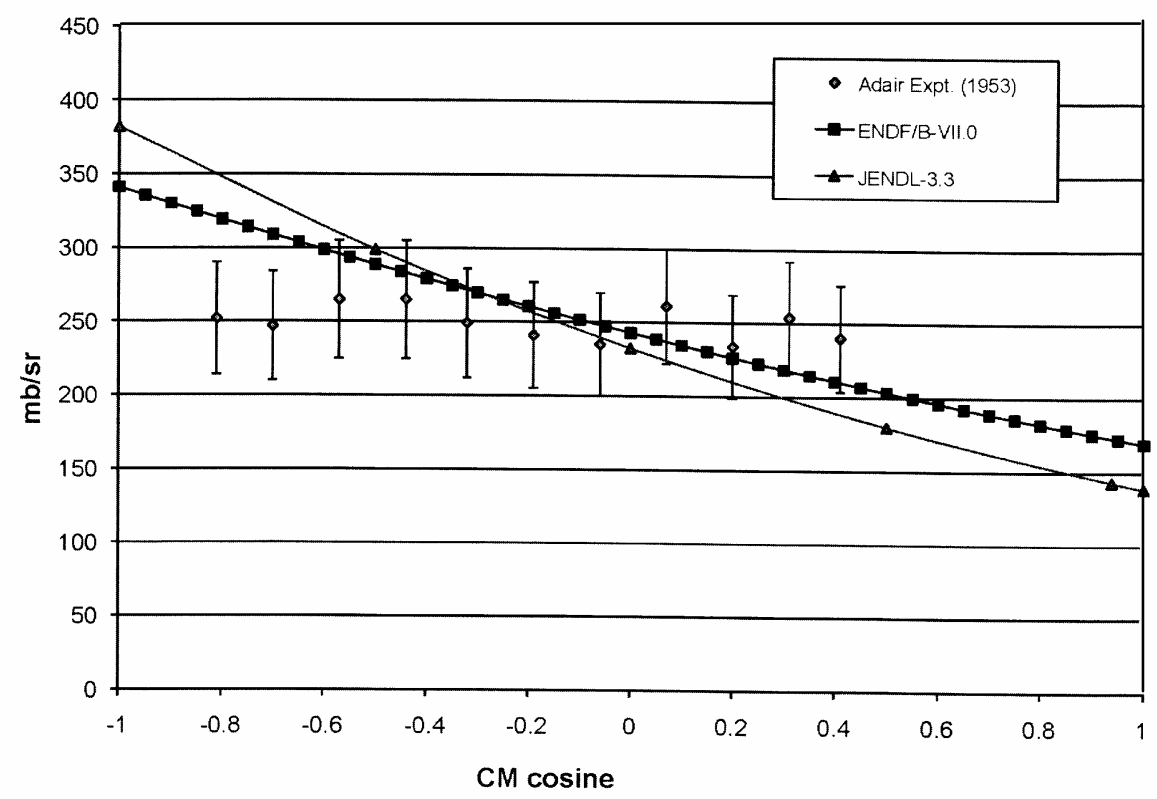

Fig. 1. Differential cross-section (mb/sr) for scattering of $220 \mathrm{keV}$ neutrons from deuterium, taken from data [1] and two nuclear DLs.

Figure 1 shows the differential cross-section for elastic neutron-deuteron scattering at $220 \mathrm{keV}$ taken from two DLs and the experimental data from Adair et al [1]. Here and in other figures, the cross-section is plotted against the parameter $\mu=\cos (\theta)$, where $\theta$ is the centre-of-mass scattering angle. Clearly, these data (published 55 years ago) favour a more isotropic distribution than do the DLs. But there is also a significant difference in slope of the two curves from ENDF/B-VI.8 and JENDL-3.3. A similar comparison at $1.0 \mathrm{MeV}$ (Fig. 2) shows less dramatic differences, but there is still a substantial discrepancy between data [2] and both DLs at back angles, as well as small differences through the entire angular range. 


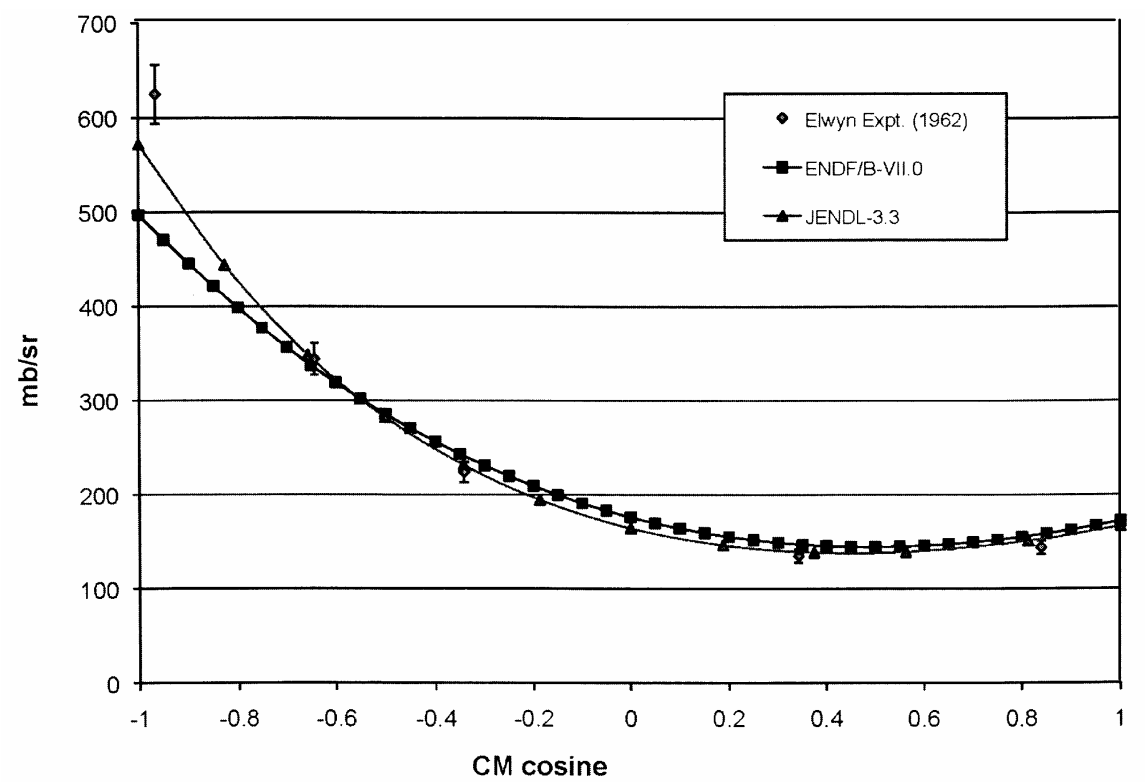

Fig. 2. As in Fig. 1 for $1.0 \mathrm{MeV}$ neutrons. Data from Elwyn et al [2].

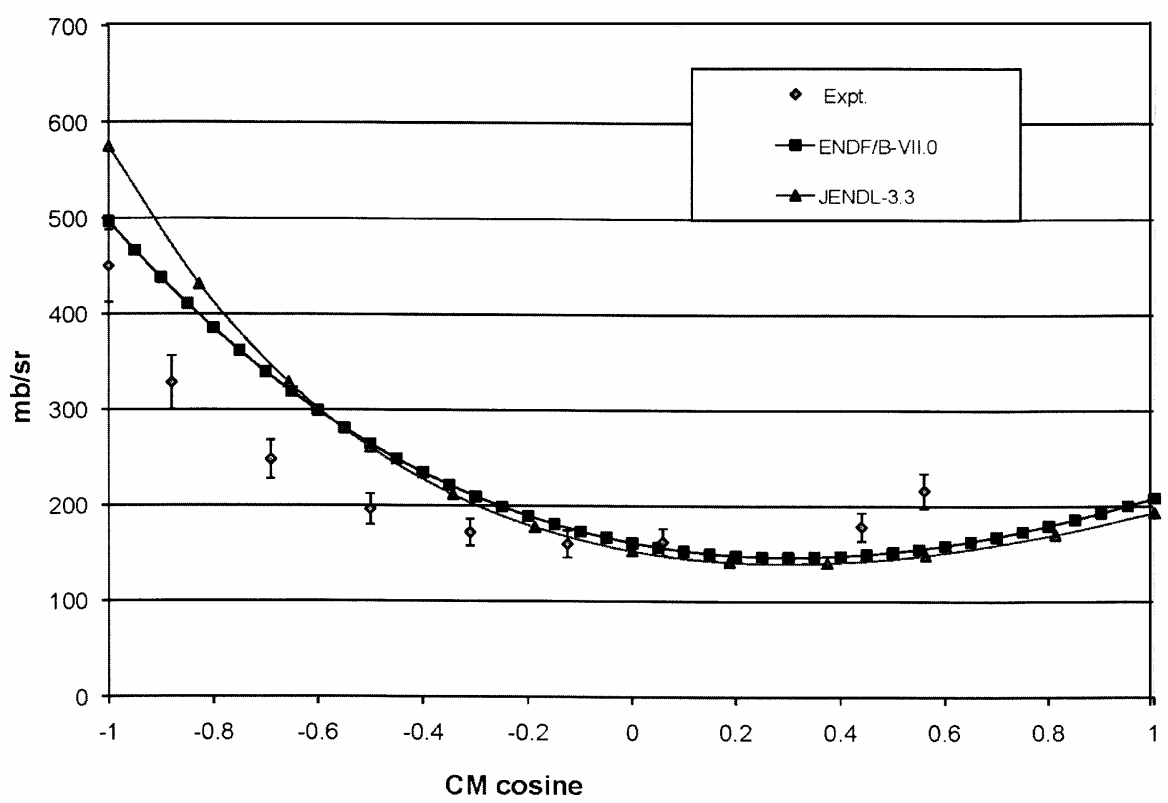

Fig. 3. As in Fig. 1 for $1.2 \mathrm{MeV}$ neutrons. Data from Vedrenne [3].

Yet, somewhat newer data from Vedrenne [3] at an energy $0.2 \mathrm{MeV}$ higher (Fig. 3) shows much greater discrepancies with both DLs, which, however, agree quite well with each other except at back angles. Such differences between the available data and the DLs persist up to $3.2 \mathrm{MeV}$, though the disagreement among DLs becomes less at the higher energies. There is a need for new experiments and for a re-evaluation of the evaluated DLs in this energy regime.

In these DLs, essentially no nuclear theory was used for obtaining the evaluated data. ENDF/B-VI.8 uses an R-matrix model to interpolate and extra- 
polate from known experimental data to obtain scattering angular distributions. JENDL 3.3 uses, in a similar way, results of very old Faddeev-type calculations [4] employing a single separable s-wave Yamaguchi NN interaction.

\section{THREE-BODY THEORY}

Neutron-deuteron scattering involves the interaction of a single uncharged nucleon (the neutron), with the ${ }^{2} \mathrm{H}$ nucleus (or deuteron). The proton-deuteron scattering, however, will not be discussed here. It involves the interaction of the ordinary hydrogen nucleus $\left({ }^{1} \mathrm{H}\right)$, or proton, with the ${ }^{2} \mathrm{H}$ nucleus. This is an easier problem for experimental study, since both particles are charged and easily detected in various modern detectors used in nuclear experiments. It is, however, a harder problem for theory, since the three-body theory that will be discussed in this section does not apply to long-range forces, such as the Coulomb interaction between charged particles. The deuteron, as stated, is the nucleus of the heavy isotope of hydrogen, ${ }^{2} \mathrm{H}$, which replaces the normal mass- 1 isotope, ${ }^{1} \mathrm{H}$, in the water molecule to make "heavy water", or $\mathrm{D}_{2} \mathrm{O}$. It is the bound state of a neutron and a proton; in fact, the only bound state of the two-nucleon system. It is weakly bound, $E_{B}=-2.26 \mathrm{MeV}$, whereas, typically, the binding energy of nuclei follow the approximate rule: $B_{E} / A \sim 7$ to $8 \mathrm{MeV} /$ nucleon, which should make the magnitude of the deuteron binding energy around 14 to $16 \mathrm{MeV}$. Consequently, it has a large radius, $2.14 \mathrm{fm}$, as compared to the typical $r=r_{0} A^{1 / 3}=1.64 \mathrm{fm}$, for $A=2$. It has a magnetic dipole moment of 0.8574 nuclear magnetons, and a quadrupole moment of $2.82 \mathrm{fm}^{2}$.

In the absence of more consistent experimental data for low-energy $n+d$ scattering, we turn to the few-body theory. Faddeev in 1961 published the complete quantum theory of the three-body system, which was later extended to a larger number of particles. Later on, Alt, Grassberger and Sandhas [5] (here to be referred to as AGS) provided an alternative formulation of the three-body problem, which has some practical advantages over Faddeev's original equations. Using accurate understanding of nucleon-nucleon (NN) interactions that fit well the NN scattering data (at least up to the pion-production threshold at $290 \mathrm{MeV}$, lab.), as well as advances in computer technology, it is now possible, with this theory, to perform precise calculations of bound states and scattering observables in three-nucleon systems.

Using the AGS formulation of the three-body equations, Canton et al [6] carried out calculations, between 3 and $19 \mathrm{MeV}$, of cross-sections and various spin observables in the $(n+d)$ system using various nucleon-nucleon interactions. Here we extend these calculations, considering the Bonn-B NN interaction, to lower energy (down to $50 \mathrm{keV}$ ), for comparison with the available data and the nuclear DLs. The AGS equation is:

$$
U_{\beta \alpha}=\bar{\delta}_{\beta \alpha} G_{0}^{-1}+\sum_{\gamma} \bar{\delta}_{\beta \gamma} T_{\gamma} G_{0} U_{\gamma \alpha} .
$$

The subscripts in this equation are the three-body 'channel' labels using the "odd-man-out" convention. That is, for example, $\alpha=1$ denotes particles 2 and 3 interacting, particle 1 free, and $\bar{\delta}_{\beta \alpha}=0$ if $\beta=\alpha$ and $\bar{\delta}_{\beta \alpha}=1$, otherwise. Equation 
(1) is written in a formal, quantum-mechanical notation: $U$ is a $3 \times 3$ matrix of operators in the full three-body Hilbert space, $G_{0}$ is an operator in this same space, being the propagator (or resolvent operator) for three free particles (the inverse of the operator $H_{0}-E$, where $H_{0}$ is the Hamiltonian for three free particles), and $T_{\gamma}$ is the scattering transition matrix ( $T$-matrix) for the two-body subsystem labelled by $\gamma$ but expressed in the full three-body Hilbert space (e.g. if $\gamma=1$, it describes the scattering between nucleons 2 and 3, with nucleon 1 as spectator). The two-body T-matrix is given in terms of the two-body potential by: $T_{\gamma}=V_{\gamma}+V_{\gamma} G_{0} T_{\gamma}$, where $V_{\gamma}$ is the NN interaction in channel $\gamma$.

The AGS equation has the advantage over Faddeev's original formulation of the three-body problem in that the 'unknowns', $U_{\beta \alpha}$, relate directly to observables. Matrix elements of the $U$-s taken between suitable incoming and outgoing states give, directly, the $T$-matrix, from which all manner of experimental observables can be extracted.

After removal of centre-of-mass motion, the AGS equation (1) is a set of coupled integral equations in two vector variables. However, with angularmomentum reduction it reduces to a set of integral equations in two radial variables. A further, and substantial, simplification comes about if the NN potentials are expressed as sums of separable terms. The AGS equation then becomes a set of integral equations in one radial variable. Therefore, in our work, we use the Graz separable representations of the realistic $\mathrm{NN}$ interactions. In particular, for the Bonn-B potential used here we have employed the BBEST potential [7].

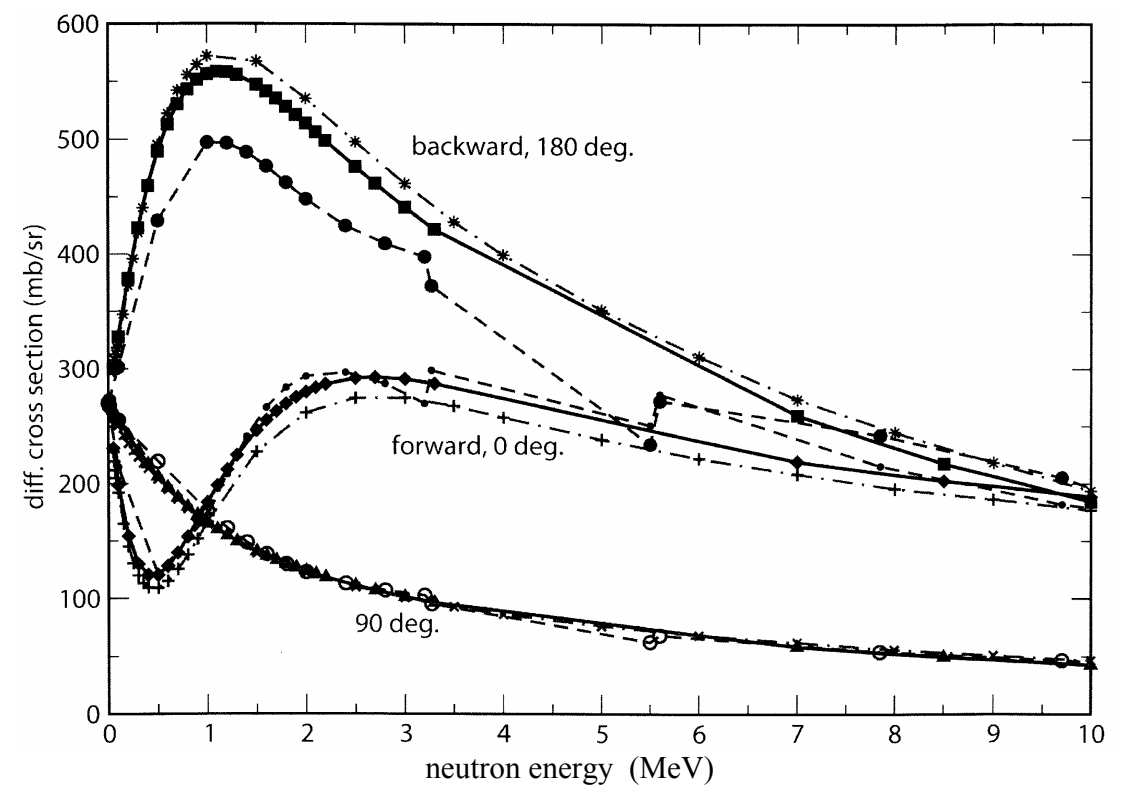

Fig. 4. Differential cross-section ( $\mathrm{mb} / \mathrm{sr}$ ) for scattering of neutrons from deuterium, at three angles; calculations compared with results from two data libraries. The results of AGS calculations with the BonnB NN interaction are indicated by solid lines and squares, diamonds and triangles for $180^{\circ}, 0^{\circ}$ and $90^{\circ}$, respectively. The ENDF/B-VII.0 library data are shown as dashed lines with closed large circles, closed small circles and open circles for $180^{\circ}, 0^{\circ}$ and $90^{\circ}$, respectively. The JENDL-3.3 library data are shown as dot-dashed lines with stars, + signs and X-s for $180^{\circ}, 0^{\circ}$ and $90^{\circ}$, respectively. 
In Fig. 4, we show the energy dependence of the differential cross-sections at zero, 90 and 180 degrees obtained from our AGS calculations (Bonn-B) and DLs ENDF/B-VII.0 [8] and JENDL-3.3. The figure shows one of the problems with DL ENDF/B-VII.0 (and ENDF/B-VI.8) ${ }^{1}$ : the discontinuity and gap in the data between $3.2 \mathrm{MeV}$ and 5.7 MeV. Also, there is considerable disagreement between that and the Bonn-B results, especially at back angles $\left(180^{\circ}\right)$. Agreement between the calculated results and the JENDL library is better, but not exact.

Figures 5 and 6 show the calculated results for differential cross-section as function of $\mu$, together with those from the same two DLs and at the same energies as in Figs. 1 and 2, respectively. It is clear that the current theoretical result favours the JENDL-3.3 DL.

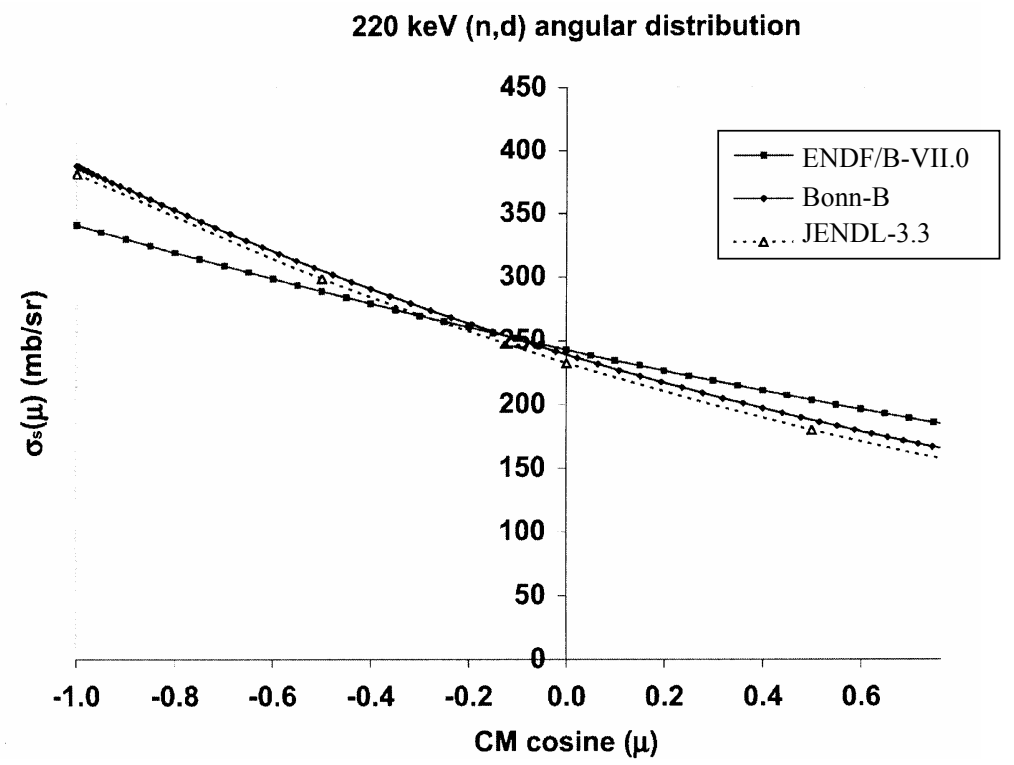

Fig. 5. Differential cross-section (mb/sr) for scattering of $220 \mathrm{keV}$ neutrons from deuterium. AGS calculations with the Bonn-BNN interaction, compared with two nuclear DLs.

This persists at other energies up to $3.2 \mathrm{MeV}$ (not shown), where there is little difference between theory and the two DLs. The strongest differences between theory and the ENDF data occur at the most extreme backward angles. But small differences are also seen at different angular ranges. It should be noted that the AGS calculations are highly accurate, given the particular choice of NN potential. In fact, we have recently carried out similar calculations with other NN interactions, such as another version of the Bonn potential, CD-Bonn and AV18, and find very little sensitivity to the choice of different realistic NN interactions. This is illustrated in Fig. 7. The results with Bonn B and the newer CD-Bonn potentials are indistinguishable, while the AV18 potential yields a slightly higher value in the forward direction.

In these theoretical results, two effects have not been included. One of them is the consequence of an irreducible three-nucleon interaction (3NF). This is discussed in Ref. [6] and affects mainly spin observables, though it may also affect

\footnotetext{
${ }^{1}$ Note that, for low-energy $n+d$ data, ENDF/B-VI.8 and ENDB/B-VII.0 are equivalent.
} 
cross-sections. Using only the 3NF of Ref. [6], the contribution of this term is not visible in the energy range shown in Fig. 8.

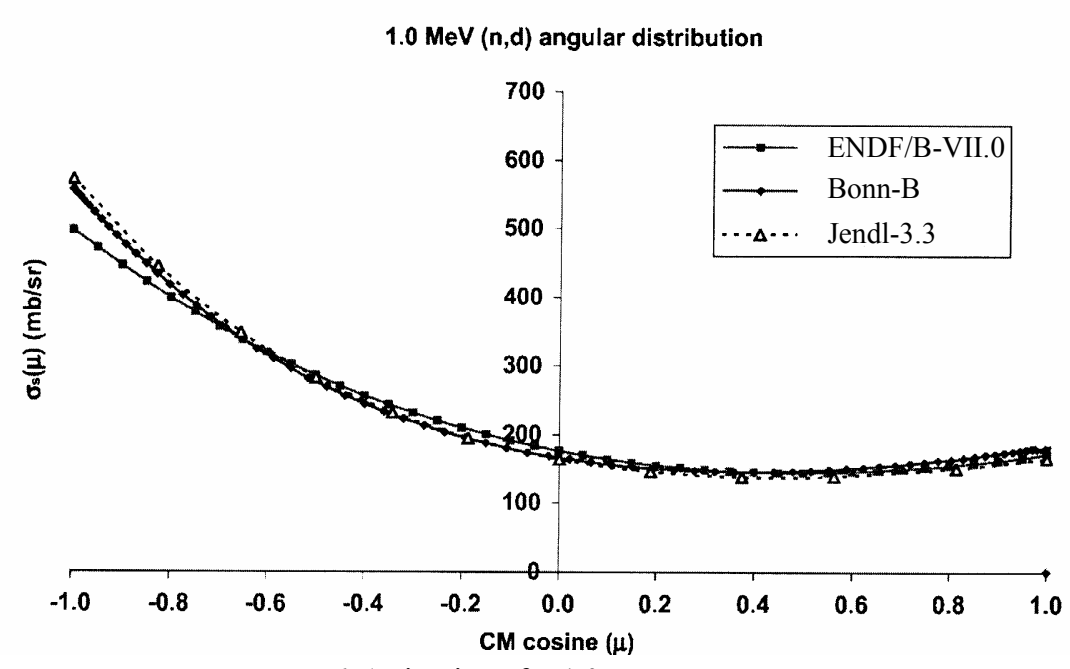

Fig. 6. As in Fig. 5 for $1.0 \mathrm{MeV}$ neutrons.

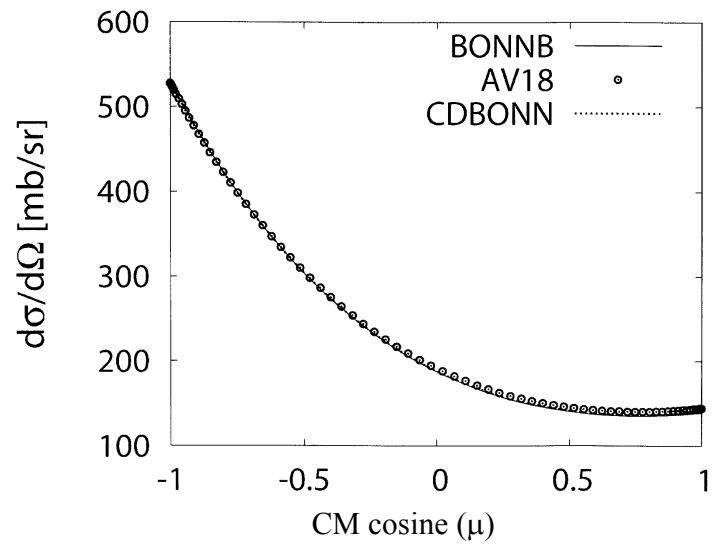

Fig. 7. Differential cross-sections with incident neutron energy of $700 \mathrm{keV}$ from different NN potentials. The axes display the same quantities as in Fig. 1.

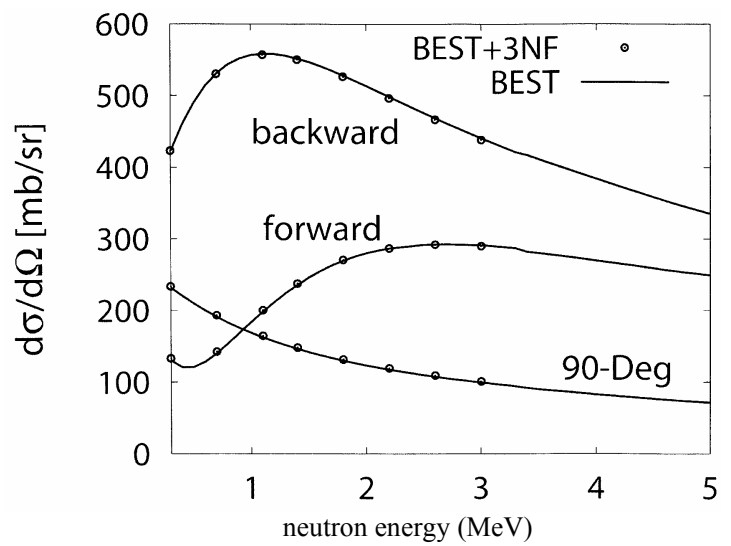

Fig. 8. Calculated $n+d$ scattering cross-sections in three directions (forward, backward, and 90 degrees), including an irreducible 3NF effect. The axes are labelled as in Fig. 4. 
However, this is not the only $3 \mathrm{NF}$ term that needs to be considered. More complete calculations of the effect of irreducible three-nucleon interactions are in progress. In addition, at low energies and especially at small angles, an electromagnetic effect, due to the interaction of the magnetic moments of the neutron and deuteron, should also be taken into account. This has not been evaluated, as yet.

\section{IMPLICATIONS FOR CRITICAL SYSTEMS CONTAINING HEAVY WATER}

Shortly after the release of ENDF/B-VI.8 in 2001, it was noticed at Los Alamos National Laboratory (LANL) that the calculated eigenvalues for a set of heavy-water solution benchmarks involving highly enriched uranium (HEU; 93.7 atom $\%{ }^{235} \mathrm{U}$ ) had decreased significantly relative to earlier versions of ENDF/BVI. Such changes resulted from modifications to the angular probability distributions for elastic scattering at energies less than $3.2 \mathrm{MeV}$. We now show the results of calculated reactivity impact for various critical systems involving heavy water based on the AGS results compared with those from DLs ENDF/B-VII.0, ENDF/B-VI.4 and JENDL-3.3.

Critical experiments have been simulated with the MCNP5 ${ }^{\mathrm{TM}^{2}}$ (Monte Carlo N-Particle) neutron transport code [8]. Here we show results based on the Atomic Energy of Canada Limited, Chalk River Laboratory ZED-2 (Zero Energy Deuterium) Coolant Void Reactivity (CVR) critical experiments. These involve low neutron leakage, heterogeneous arrangements of lattices of natural-uranium (NU; 0.71 atom $\%{ }^{235} \mathrm{U}$ ) fuel rods. There exist numerous such experiments with various fuel types, coolants, lattice pitches and arrangements. The experiments are modern and ongoing. The experimental uncertainty in any $k_{\text {eff }}$ (the neutron multiplication constant $^{3}$ ) determination is estimated to be $\pm 0.2 \mathrm{mk}$, dominated by measurement uncertainty of the $\mathrm{D}_{2} \mathrm{O}$ purity. Also, the MCNP model of ZED-2 is quite detailed and extends outward to include the surrounding concrete shielding.

Two typical pairs of experiments involving $\mathrm{D}_{2} \mathrm{O}$-cooled and air-cooled (voided) experiments were chosen. Both sets involve 55 fuel channels of 28element $\mathrm{NU} \mathrm{UO}_{2}$ fuel bundles similar to those used in the Pickering CANDU ${ }^{\circledR 4}$ power reactors. Each fuel channel contains a vertical stack of five fuel bundles contained inside concentric aluminium tubes that mimic the zirconium-alloy pressure tube and calandria tube of a real CANDU fuel channel. The lattice arrangement is a regular triangular/hexagonal lattice array with a pitch of $31.0 \mathrm{~cm}$.

The ZED-2 $k_{\text {eff }}$ results show a rising trend with calculated neutron leakage. Since the leakage increases when air is substituted for $\mathrm{D}_{2} \mathrm{O}$ coolant, the $k_{\text {eff }}$ bias (i.e., the difference between the calculated $k_{\text {eff }}$ and 1.0) also increases. This gives rise, in turn, to a small positive coolant void reactivity (CVR) bias - defined here as the difference between the $k_{\text {eff }}$ bias for the air-cooled and $\mathrm{D}_{2} \mathrm{O}$-cooled cases. The

\footnotetext{
${ }^{2}$ MCNP5 $^{\mathrm{TM}_{\mathrm{is}}}$ a trademark of the Regents of the University of California, Los Alamos National Laboratory.

$3 k_{\text {eff }}$ is the neutron multiplication constant for a system undergoing nuclear fission; that is, the ratio of the neutrons produced in successive generations. $k_{\text {eff }}=1.0$ for a critical system.

4 CANDU $^{\mathbb{B}}$ (CANADA Deuterium Uranium) is a registered trademark of Atomic Energy of Canada Limited (AECL).
} 
smaller the magnitude of the CVR bias, the better job MCNP5 does of calculating the reactivity perturbation associated with $\mathrm{D}_{2} \mathrm{O}$ coolant voiding when using a particular nuclear DL.

The MCNP5 simulations were performed using the nuclear data library ENDF/B-VII.0 that was released officially in December, 2006. The corresponding $\mathrm{ACE}^{5}$-format files needed to execute MCNP5 were prepared by the U.S. National Nuclear Data Center and distributed by the Radiation Safety Information Computational Center (RSICC). Four calculations were performed (Fig. 9), changing just the ACE file for ${ }^{2} \mathrm{H}$ :

1. ENDF/B-VII.0: this is the reference case. It is based on an R-matrix analysis and, hence, also incorporates information from experiments using positive ion beams.

2. Bonn-B: this uses a modified ENDF/B-VII.0 file for ${ }^{2} \mathrm{H}$ in which the Bonn$B$ results were implanted for both the total elastic scattering cross-section and the energy/angle scattering probability distribution over the energy range from $50 \mathrm{keV}$ to $10 \mathrm{MeV}$. A corresponding ACE file was then generated using the NJOY99.0 cross-section data processing code.

3. ENDF/B-VI.4: this uses an ACE file for ${ }^{2} \mathrm{H}$ that was produced by LANL. The $(n+d)$ data are the same as for ENDF/B-VI.0 through VI.4.

4. JENDL-3.3: this uses an ACE file from RSICC for ${ }^{2} \mathrm{H}$ corresponding to the current Japanese DL. It is based on the old Faddeev's model calculations.

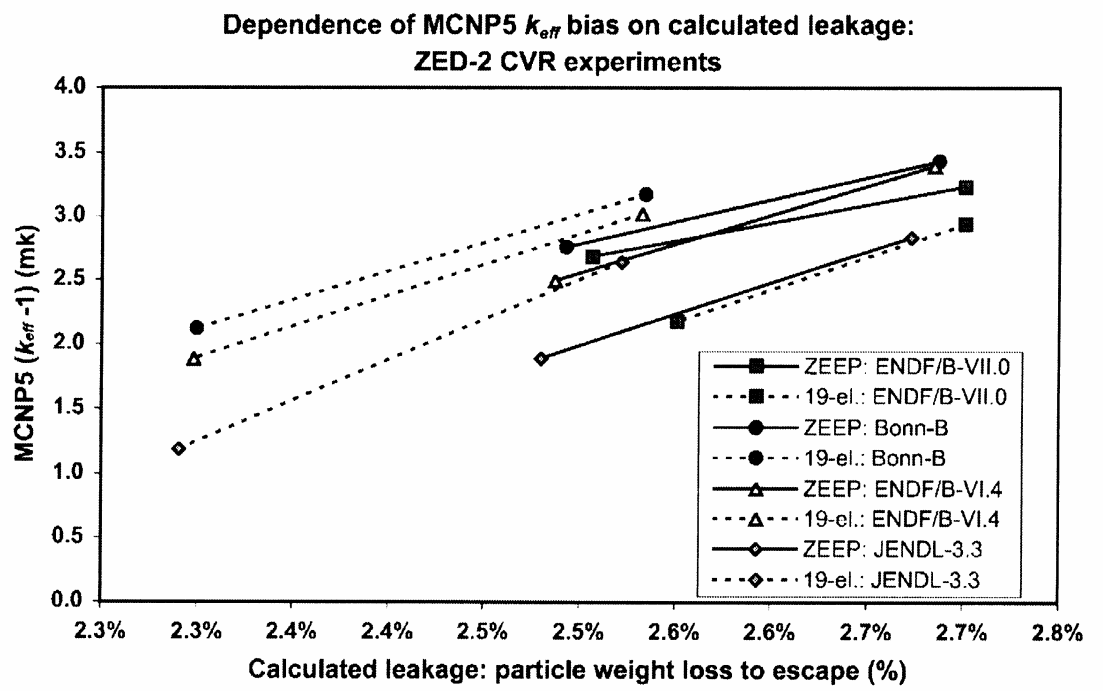

Fig. 9. MCNP5 ZED-2 $k_{\text {eff }}$ bias results for selected CVR experiments: dependence on the calculated neutron leakage.

For the ZED-2 results in Fig. 9: (1) The $k_{\text {eff }}$ bias is the highest with Bonn-B $(2.87 \mathrm{mk})$, slightly lower with ENDF/B-VII.0 $(2.76 \mathrm{mk})$ and VI.4 $(2.70 \mathrm{mk})$, and the lowest with JENDL-3.3 (2.14 mk). (2) The CVR bias with Bonn-B (0.86 mk) is only slightly higher than ENDF/B-VII.0 (0.66 mk), slightly smaller than ENDF/ B-VI.4 (1.02 mk), and quite a bit better than JENDL-3.3 (1.20 mk).

${ }^{5}$ A Compact ENDF. 


\section{THE CANDU SYSTEM}

ZED-2 simulations and experiments of the type discussed in the previous section are important to the CANDU (which stands for Canada Deuterium Uranium) system of nuclear power reactors since they provide essential and precise data for validating the computer codes and associated data used in the power reactor design and safety assessment. In CANDU reactors, natural uranium $(0.7 \%$ ${ }^{235} \mathrm{U}$ ) is used in the fuel rods, and heavy water, $\mathrm{D}_{2} \mathrm{O}$, is used as both the neutron moderator and the primary means of removing the generated heat from the reactor core. The reliance on dependable nuclear data for $n+d$ elastic scattering of such systems is the link between Nuclear Theory and Nuclear Power of the title of this article. The CANDU reactors have been used for power generation in Canada (in the provinces of Ontario, Quebec and New Brunswick) since 1968. A number of CANDU reactors have also been sold overseas. Table 1 lists the operating CANDU 6-type reactors as of 2003.

CANDU 6 units in operation (as of 2003).

The output is given in MW; the capacity factor is the \% of time the unit is operating at the capacity

\begin{tabular}{|l|l|c|c|c|}
\hline \multicolumn{1}{|c|}{ Unit } & \multicolumn{1}{|c|}{ Location } & Start date & Output, MWe & Capacity factor, \% \\
\hline Point Lepreau & Canada & 1983 & 680 & 82.4 \\
\hline Wolsong1 & S. Korea & 1983 & 679 & 85.8 \\
\hline Gentilly 2 & Canada & 1983 & 675 & 79.5 \\
\hline Embalse & Argentina & 1984 & 648 & 85.3 \\
\hline Ceranvoda1 & Romania & 1996 & 648 & 87.5 \\
\hline Wolsong2 & S. Korea & 1997 & 715 & 94.0 \\
\hline Wolsong3 & S. Korea & 1998 & 715 & 95.1 \\
\hline Wolsong4 & S. Korea & 1999 & 715 & 97.2 \\
\hline Qinshan1 & China & 2002 & 728 & 87.7 \\
\hline Qinshan2 & China & 2003 & 728 & 86.1 \\
\hline
\end{tabular}

Subsequently, a second CANDU 6 unit entered into service at Cernavoda, Romania, in November 2007. As well, numerous reactors based on earlier and later CANDU versions with various power outputs are currently operating at the Pickering, Bruce and Darlington Nuclear Generating Stations in Ontario as well as in India and Pakistan.

AECL is presently developing the ACR-1000 ${ }^{\mathrm{TM}^{6}}$ [9], which is an evolution of the CANDU concept. ACR-1000 still uses heavy water as moderator, but normal water, $\mathrm{H}_{2} \mathrm{O}$, as coolant. This results in a reduction in expensive heavy water inventory by about two thirds, and less loss of heavy water. The fuel is Low-Enriched Uranium (LEU) rather than natural uranium. The enrichment is up to $2.5 \%{ }^{235} \mathrm{U}$. This enables a more compact reactor core, higher stability and greater power output

${ }^{6} \mathrm{ACR}^{\mathrm{TM}}$ (Advanced CANDU Reactor) ${ }^{\mathrm{TM}}$ is a trademark of AECL. 
(approximately $1200 \mathrm{MW}$ electrical power output initially). The reactor design calls for a small negative coolant void reactivity feedback coefficient over the entire operating range, for improved passive safety. It is mainly to ensure a good understanding of this reactivity coefficient that the theory of neutron-deuteron scattering plays a significant role. In addition, a new set of neutron-deuteron scattering experiments is in an advanced planning stage by an international collaboration.

\section{CONCLUSIONS}

The neutron-deuteron system is a fundamental system for understanding nuclear interactions at a fundamental level, and a test of three-body theories. In addition, this system is a key ingredient of many nuclear power systems, such as the CANDU system. Nuclear power has returned to consideration as the energy demands continue to increase, especially in rising economies such as China and India, while the price of crude oil skyrockets and supplies diminish. Conservation measures and renewable sources, alone, cannot meet the rapidly increasing demand. Besides, nuclear is an energy source that does not release carbon dioxide, an important greenhouse gas.

In this study, we conclude that, if the ENDF/B-VII.0 data for ${ }^{2} \mathrm{H}$ are flawed, our next preference, based on the lower CVR bias value, is theoretical results from AGS calculations using the Bonn-B NN interaction. Our other main conclusion is that modern nuclear model calculations produce results for practical applications that are noticeably different and likely better than those based on older Faddeev calculations with a simple Yamaguchi potential. This leads to a more general conclusion: in the future nuclear data evaluations one should pay more attention to the availability of modern theoretical approaches to nuclear structure and reaction information, especially for few-nucleon systems. Finally, in the case of low-energy neutron-deuteron differential scattering cross-sections, theory must be complemented by new precise measurements.

\section{ACKNOWLEDGEMENTS}

The work has been supported in part by AECL and NSERC (Canada) and by MIUR-PRIN (Italy).

\section{REFERENCES}

1. Adair, R.K., Okazaki, A. and Walt, M. (1953). Phys. Rev., 89, 1165.

2. Elwyn, A.J., Lane, R.O. and Langsdorf, A. Jr. (1962). Phys. Rev. 128, 779.

3. Vedrenne, G. (1966).Journal de Physique - Colloque, 27, 71.

4. Ebenhöh, W. (1972). Nucl. Phys. A191, 97.

5. Alt, E.O., Grassberger, P. and Sandhas, W. (1967).Nucl. Phys. B2, 167.

6. Canton, L., Schadow, W. and Haidenbauer, J. (2002). Eur. Phys. J. A 14, 225.

7. Haidenbauer, J., Koike Y., and Plessas, W. (1987). Phys. Rev. 33, 439.

8. Kozier, K.S. (2008). In: Proceedings of the International Conference on Nuclear Data for Science and Technology, April 22-27, 2007, Nice, France, eds. O. Bersillon, F. Gunsing, E. Bauge, R. Jacqmin, and S. Leray, EDP Sciences, pp 915-918. 
9. Michaela Ovanes, P.S.W. Chan and J. Hopwood, (2007). Paper Log \#7250. In: Proceedings of the International Congress on Advances in Nuclear Power Plants, ICCAP2007 "The Nuclear Renaissance at Work”, Nice Acropolis, France, May 13-18.

\author{
KODOLTEORIJA - KODOLENERĢIJA ${ }^{7}$ \\ Juris P. Svenne, L. Canton, un K.S. Kozier
}

Kopsavilku ms

Modernās kodolteorijas rezultāti ir pietiekami precīzi un uzticami, lai tos izmantotu praktiskajos pielietojumos, sevišksi kodolenerǵētikai svarīgu daudznuklonu sistēmu izkliedē. Izmantojot vispāratzītu nuklonu-nuklonu (NN) mijiedarbības teoriju, kas labi apraksta NN izkliedes datus un trīsdaḷiņu teorijas AGS formu, mēs veicām precīzus zemas enerǵijas neitronu-deitronu izkliedes aprēķinus. Mēs parādām, ka trīsnuklonu spēku efekti, kas ietekmē zemas energíjas vektoru analīzes spēku, praktiski neietekmē n-d izkliedes šçērsgriezuma leņ̧̧isko sadalījumu. Šķkiet, ka ar šīs izkliedes datiem ENDF novērtēto kodolu datu bibliotēkā pie izejas neitrona enerğijām mazākam par $3.2 \mathrm{MeV}$, ir problēmas. Atbalstošie eksperimentālie dati ir diezgan veci $(>25$ gadiem), reti un bieži pretrunīgi. Mūsu trīsķermeņu problēmas rezultāti pie zemām enerğijām no $50 \mathrm{keV}$ līdz $10,0 \mathrm{MeV}$ tika salīdzināti ar ENDF.B VII.0 un JENDL-3.3 novērtētajiem leņ̧̧̧iskajiem sadalījumiem. Ir parādīta šo rezultātu ietekme uz dažādu kritisku sistēmu, kas satur smago ūdeni $\mathrm{D}_{2} \mathrm{O}$, aprēķināto reaktivitāti.

08.08.2008.

\footnotetext{
${ }^{7}$ Šì raksta pamatā ir referāts, ko autori nolasīja LZA 2007. gada 24. augustā.
} 